Haya: The Saudi Journal of Life Sciences

Abbreviated Key Title: Haya Saudi J Life Sci ISSN 2415-623X (Print) |ISSN 2415-6221 (Online) Scholars Middle East Publishers, Dubai, United Arab Emirates Journal homepage: https://saudijournals.com/sjls

Review Article

\title{
Biochemistry of Fat Soluble Vitamins, Sources, Biochemical Functions and Toxicity
} \author{
Rizwana Jabeen ${ }^{1}$, Sobia Tariq ${ }^{1}$, Iqra Shehzadi ${ }^{1}$ \\ ${ }^{1}$ Department of Biochemistry, University of Agriculture, Faisalabad \\ ${ }^{2}$ Department of Zoology, Wildlife and Fisheries, University of Agriculture, Faisalabad \\ ${ }^{3}$ College of Food Science and Technology, Huazhong Agricultural University, China
}

Hamza Rafeeq ${ }^{1 *}$, Sufyan Ahmad², Muhammad Burhan Khan Tareen ${ }^{3}$, Khalil Ahmad Shahzad², Awais Bashir ${ }^{2}$,

DOI: $10.36348 /$ sjls.2020.v05i09.007 $\quad$ | Received: 16.09 .2020 | Accepted: 24.09.2020 | Published: 30.09 .2020

*Corresponding author: Hamza Rafeeq

\section{Abstract}

Vitamin is an organic molecule or chemical compounds that is an important micronutrient which is required to act properly in limited amounts for the digestion of the organism. Vitamins are either water-soluble or fat-soluble. Many vitamins do not exist in individual molecules, but belong to similar classes known as vitamers. The multiple functions of vitamin A are essential for growth and development, immune system maintenance and good vision. This vitamin is essential for proper vision by incorporating retinal molecules that absorb light and work during dim light and color differentiation. Due to the unusual role of the retinal as a visual chromophore, vision loss, especially in reduced light. Vitamin D belongs to a class of fat-soluble secosteroids that enhance the absorption of calcium, magnesium and phosphate by the lower intestine and other biological effects. Diet vitamin D is biologically inactive or derived from the synthesis of the skin. Vitamin D controls calcium homeostasis and its metabolism. Vitamin E is a fat-soluble antioxidant that inhibits reactive oxygen species from cell membrane protection. Several biological roles have been postulated, including a fat-soluble antioxidant. Vitamin E serves as a radical scavenger and supplies free radicals with hydrogen (H) atoms. Vitamin $\mathrm{K}$ refers to fat-soluble vitamins present in fruit and sold for structurally similar dietary products. For the modulation of certain blood-coagulation proteins or the control of calcium binding in bones and other tissues, the human body requires vitamin $\mathrm{K}$.

Keywords: Vitamins, fat soluble vitamins, Vitamin A, Vitamin D, Vitamin E.

Copyright @ 2020: This is an open-access article distributed under the terms of the Creative Commons Attribution license which permits unrestricted use, distribution, and reproduction in any medium for non-commercial use (NonCommercial, or CC-BY-NC) provided the original author and source are credited.

\section{INTRODUCTION}

Vitamin is an organic molecule (or chemical compounds, i.e. vitamers) that is an important micronutrient which is required to act properly in limited amounts for the digestion of the organism. Some reports list 14 vitamins, including choline and other major health authorities reported 13 vitamins: A, B1, B2, B3, B5, B6, B7, B9, B12, C, D, E and K. Vitamins are either water-soluble or fat-soluble. Many vitamins do not exist in individual molecules, but belong to similar classes known as vitamers. Vitamin E, for instance, comprises 4 tocopherols and 4 tocotrienols. There are thirteen vitamins in humans: four fat soluble (A, D, E, and K) and nine water soluble (vitamin B complex and vitamin C). Water-soluble vitamins dissolve rapidly in water and are usually easily excreted by the body. Because they are not processed too soon, a steady intake is important. Fat soluble vitamins are processed through the intestine using lipids (fats). The body can accumulate vitamins A and D that can lead to dangerous hypervitaminosis. Fat-soluble malabsorption vitamin deficiency is especially important in cystic fibres[1,2] 
Table-1: An overview of fat soluble vitamins

\begin{tabular}{|l|l|l|l|l|}
\hline Vitamin & Function & Deficiency & Dietary source & $\begin{array}{l}\text { RDA (Adult } \\
\text { male/female) }\end{array}$ \\
\hline Vitamin A & $\begin{array}{l}\text { Improves vision, cell } \\
\text { growth and immune } \\
\text { function }\end{array}$ & $\begin{array}{l}\text { Night blindness, } \\
\text { Hyperkeratosis } \\
\text { Keratomalacia }\end{array}$ & $\begin{array}{l}\text { Fish, liver, dairy products, orange, } \\
\text { ripe yellow fruits, leafy } \\
\text { vegetables, carrots and pumpkin }\end{array}$ & $900 \mu \mathrm{g} / 700 \mu \mathrm{g}$ \\
\hline Vitamin D & $\begin{array}{l}\text { Regulation of calcium and } \\
\text { maintenance of } \\
\text { phosphorus level in body }\end{array}$ & $\begin{array}{l}\text { Rickets, } \\
\text { Osteomalacia }\end{array}$ & Eggs, liver and fish & $15 \mu \mathrm{g} / 15 \mu \mathrm{g}$ \\
\hline Vitamin E & Act as antioxidant & $\begin{array}{l}\text { very rare } \\
\text { Mild hemolytic } \\
\text { anemia in infants }\end{array}$ & $\begin{array}{l}\text { Fruits and vegetables, nuts and } \\
\text { seeds, and seed oils }\end{array}$ & $15 \mathrm{mg} / 15 \mathrm{mg}$ \\
\hline Vitamin K & $\begin{array}{l}\text { Involved in synthesis of } \\
\text { proteins and blood } \\
\text { clotting mechanism }\end{array}$ & Bleeding diathesis & $\begin{array}{l}\text { Leafy green vegetables such as } \\
\text { spinach, egg yolks and liver }\end{array}$ & $110 \mu \mathrm{g} / 120 \mu \mathrm{g}$ \\
\hline
\end{tabular}

The multiple functions of vitamin $\mathrm{A}$ are essential for growth and development, immune system maintenance and good vision. This vitamin is essential for proper vision by incorporating retinal molecules that absorb light and work during dim light and color differentiation. The primary source of vitamin A in foods of animal origin is ester, mostly retinyl palmitate, which is processed into retinol in the small intestine. The type of retinol serves as the storage form of the vitamin and is convertible to and from retinal aldehyde into a physically active type of retinol [3].

Diet vitamin $\mathrm{D}$ is biologically inactive or derived from the synthesis of the skin. The activation of the protein enzyme involves two hydroxylating steps, one in the liver and the other in the kidneys. Deficiency leads to reduced bone mineralization and bone degradation due to bone softening disorders, including childhood rickets and adult osteomalacia[4].

Vitamin E was observed in 1922 and first synthesised in 1935 and isolated in 1938. The Greek word tocopherol name means birth and bears or holds, since the production of vitamins was initially recognised as necessary for the contribution of fertilised eggs to life (in rats). Alpha-tocopherol or, more generally, synthetic-tocopheryl acetate, naturally derived from vegetable oils, is marketed on its own or in the form of a nutritional supplement, as well as in oils or skin lotions [5].
Vitamin $\mathrm{K}$ refers to fat-soluble vitamins present in fruit and sold for structurally similar dietary products. For the modulation of certain bloodcoagulation proteins or the control of calcium binding in bones and other tissues, the human body requires vitamin $\mathrm{K}$ [6].

The aims of this review article investigated aspects of the sources, biochemistry, excretion and toxicity of the fat soluble vitamins, for the clear determination of the sequences of amino acids of particular amino acids that are involved in synthesis of the proteins, investigate the genes for function of the human body involved in development as well as functional information about structure of the fat soluble vitamins.

\section{Fat soluble vitamins \\ Vitamin A}

Vitamin A consists of a group of unsaturated organic dietary compounds including retinol, retinal and other carotenoids of provitamin A (mainly betacarotene). The multiple functions of vitamin $\mathrm{A}$ are essential for growth and development, immune system maintenance and good vision. This vitamin is essential for proper vision by incorporating retinal molecules that absorb light and work during dim light and color differentiation. Vitamin $\mathrm{A}$ is therefore somewhat distinct from retinoic acid, which provides an essential hormonal growth factor for epithelial and other cells as an irreversibly oxidized source of retinol [7].

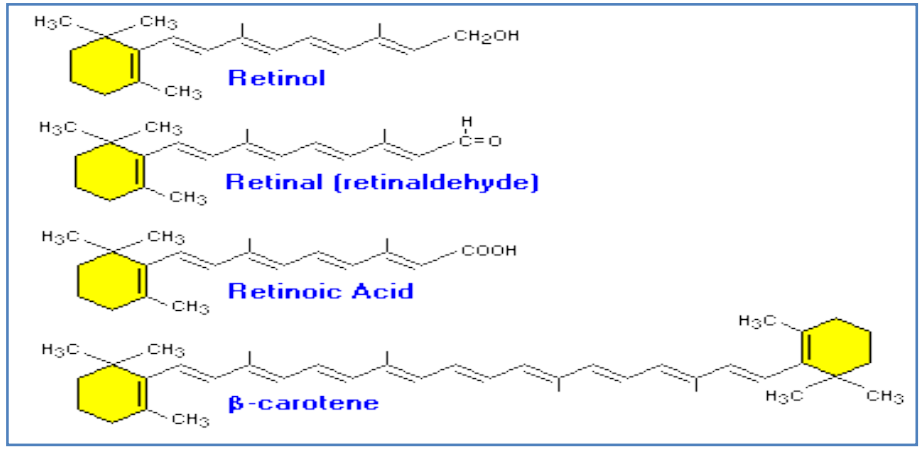

Fig-1: Structure of Vitamin A and its analogues 
The primary source of vitamin A in foods of animal origin is ester, mostly retinyl palmitate, which is processed into retinol in the small intestine. The type of retinol serves as the storage form of the vitamin and is convertible to and from retinal aldehyde into a physically active type of retinol. The beta-ionone ring attached to the isoprenoid chain, called the retinyl group, is present in all types of vitamin A. Both structural characteristics are important for vitamin activity. The coloured carrot compound (beta carotene) can be described as two related retinyl groups that lead to vitamin A levels in the body. $\alpha$ and carotenes also provide a single group of retinyl that has some vitamin activity. In the other carotenes, there is no vitamin activity. Beta-cryptoxanthin carotenoid has an ionone group and shows vitamin activity in humans [8].

Two main food sources of vitamin A can be found are Retinol is a yellow, fat-soluble material obtained from the consumption of animal food products. Since the source of pure alcohol is unstable, the vitamin is contained in the tissue as retinyl ester as well as $\alpha, \beta$ and carotenes and beta-cryptoxanthin xanthophyll, all of which are beta-ionone clusters, serve as provitamin $\mathrm{A}$ in herbivores and omnivores. These animals have a beta-carotene 15,15'-dioxygenase enzyme that cleaves beta-carotene and converts to retinol in the intestinal mucosa[9].

\section{Functions}

Following are the functions of vitamin A essential for vision and eye health. Retinal, the active vitamin A type, is the required colour vision and lowlight perception molecule that incorporates the opsin protein to form Rhodopsin. The cornea and the conjunctiva also help to protect and maintain it. Significant dietary use of vitamin A helps to reduce disorders such as age-related macular degeneration (AMD). The increased concentrations of $\alpha$ and $\beta$ carotenes and $\beta$-cryptoxanthin reduce the risk of AMD by up to $25 \%$ in experiments. This reduction is linked with required amount of carotenoids in macular tissue [10].

Vitamin A precursors are carotenoids ( $\alpha$ and $\beta$ carotenes and $\beta$-cryptoxanthin) which have antioxidant function. Carotenoids are resistant to free radicals highly reactive oxidative stress molecules that can destroy the body. A number of chronic disorders, such as diabetes, stroke, respiratory failure and cognitive impairment, are related to oxidative stress. Carotenoidhigh diets pose a reduced risk for many other diseases, including coronary heart disease, lung cancer and diabetes. Vitamin A is a vital precursor to the proper functioning of the immune system. It plays a vital role in the differentiation and division of Tcells. The IL2 level is increased during its functioning. Conversion of $\mathrm{T}$ cells to regulatory $\mathrm{T}$ cells in dentritic cells is also mediated with this vitamin. Regulatory cells are essential to the immune response. Vitamin A, along with TGF- $\beta$, facilitates the transformation of $\mathrm{T}$ cells into regulatory $\mathrm{T}$ cells. TGF- $\beta$ promotes $\mathrm{T}$-cell differentiation without vitamin $\mathrm{A}$, which can cause an autoimmune response [11].

Vitamin A is important for fertility in both men and women because it is vital for the formation of sperm and eggs. It is also important for the development and maintenance of placental health, foetal tissue and foetal growth. Vitamin A is also important to maternal and foetal health. Fruit and vegetables high in carotenoids can protect against different types of cancer due to their antioxidant properties. Data from more than 10,000 people, among other factors, showed that $46 \%$ and $61 \%$ have a lower chance of developing lung cancer than those who are not fumigators with the lowest levels of alpha-carotene and beta-cryptoxanthene in the blood. In vitro studies have confirmed that retinoids would inhibit the growth of certain cancer cells, including colon, breast and ovarian carcinoma [12].

\section{Sources}

Functional vitamin A concentrations are highest in liver and fish oils. Milk and chickens, which also contain some provitamin A, are key forms of vitamin A functionality. Provitamin A is most commonly derived from leafy green vegetables, orange and yellow vegetables, onions, apples and some vegetable oils. Vitamin A's leading food includes dairy products, liver, fish and heavy grains; carrots, broccoli, cantaloupe and squash are among the main sources of provitamin A [13].

\section{Deficiency}

Due to the unusual role of the retinal as a visual chromophore, vision loss, especially in reduced light - night blindness, is one of the most primitive and peculiar symptoms of vitamin A deficiency. Persistent deficiency contributes to a variety of alterations that are most damaging to the eyes. Such skin abnormalities are referred to as xerophthalmia. The conjunctiva is dry (xérose) at first as the keratinized epithelium replaces the usual lacrimal and mucosal epithelium. The keratin particles are then dispersed into small plaques and the rugged corneal surface slowly deteriorates, resulting in total blindness that may weaken or damage the cornea (keratomalacia). Additional modifications include decreased immunity (increased risk of ear and urinary tract infection), hyperkeratosis (white follicle lumps) keratosis, and epithelial squamous metaplasia that connects the upper respiratory and urinary tract pathways to the keratinized epithelium. Vitamin A deficiency may lead to dental enamel hypoplasia [14].

\section{Toxicity}

Acute vitamin A signs and symptoms may include fatigue, vomiting, lack of appetite, stomach pain, dizziness, irritability, sleepiness, increased cerebral oedema resulting in intercranial pressure, rash, 
peeling skin, coma and death. Chronic vitamin A signs and symptoms may include splenomegaly, hepatomegaly, extreme headaches and brain pseudotumors, rash, thin and dirty hair, eyebrow alopecia, scratching and dry eyes, raw or gross lips and swollen or broken lips, cortical bone hyperostosis, arthralgia and simple fractures. Vitamin A toxicity in children includes irritability, somnolence, delirium, coma, interkranium pressure increase, bulging fontanelles (in children), behavioural changes, brain oedema, bulging eyeballs, brain swelling, vision defects, skin discoloration and scratching[15].

\section{Vitamin D}

Vitamin D belongs to a class of fat-soluble secosteroids that enhance the absorption of calcium, magnesium and phosphate by the lower intestine and other biological effects. Vitamin D3 (also referred to as cholecalciferol) and vitamin D2 (ergocalciferol) are the most important compounds in humans [16].

\section{Synthesis}

Diet vitamin $\mathrm{D}$ is biologically inactive or derived from the synthesis of the skin. The activation of the protein enzyme involves two hydroxylating steps, one in the liver and the other in the kidneys. Since the majority of mammals can be synthesized in sufficient quantities when exposed to the sun, it is not vital to obtain it through a dietary source. Instead, activation of the pro-hormone vitamin $\mathrm{D}$, which results in an active form of calcitriol, which then has effects through a nuclear receptor in many ways [16].

Cholecalciferol is converted to calcidiol (25hydroxycholecalciferol) in the liver; ergocalciferol is converted to 25-hydroxyergocalciferol. These two metabolites of vitamin D are measured in serum to determine the status of one vitamin D (Pittas et al., 2010). Calcidiol is hydroxylated to produce the organically active component of vitamin D, calcitriol, through the kidneys. Calcitriol circulates as a hormone in the blood, which plays a significant role in controlling the calcium and phosphate content and in encouraging stable bone development and reformulation. Calcitriol effects also include cell formation, neuromuscular and immune function, and reduction of inflammation in some cases[17].

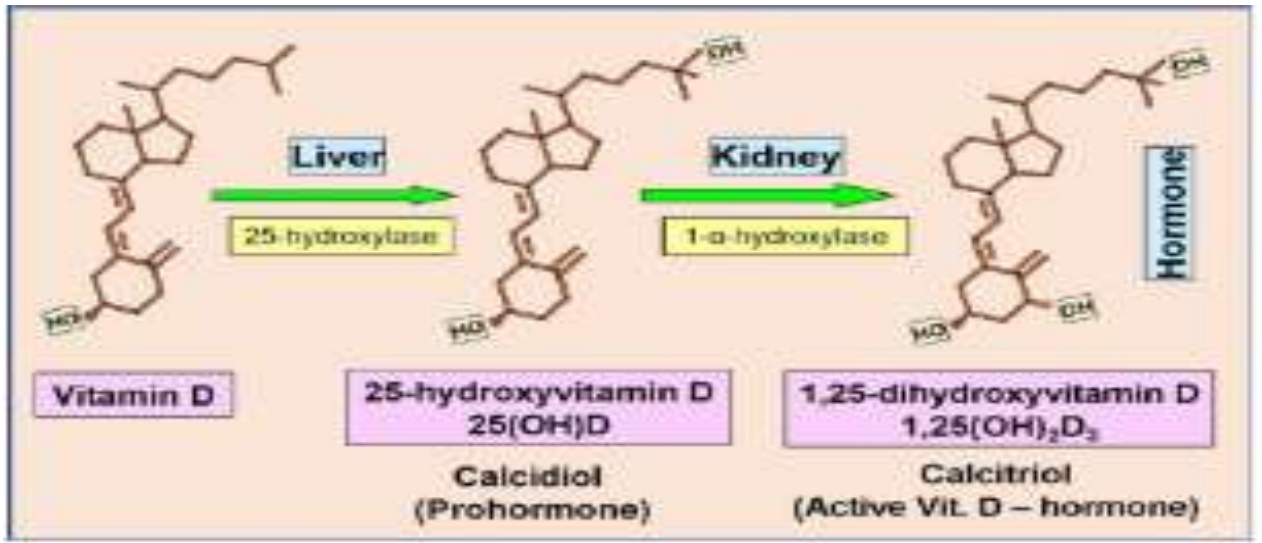

Fig-2: Conversion of provitamin D to its active form (calcitriol)

\section{Functions}

Vitamin D controls calcium homeostasis and its metabolism. Parathyroid hormone (PTH) is released to assist $25(\mathrm{OH}) \mathrm{D}$ hydroxylation as calcium blood levels decrease. Both PTH and 1,25(OH) 2D stimulate bone calcium and promote intestinal and renal calcium absorption. Vitamin D also has the ability, in its active form, to alter cell function, cell division and cell proliferation and can therefore play an essential part in physiology and health. The association of vitamin D receptors in various tissues, such as the immune system, brain, heart, pancreas and intestine, may be established in a wide range of conditions such as type 1 and type 2 diabetes, multiple sclerosis, and certain cancers[18].

\section{Sources}

Chlecalciferol synthesis in the lower epidermis of the skin was the primary natural source of this vitamin due to a sun-dependent chemical reaction (especially UVB radiation). Diet and supplements make it possible to consume cholecalciferol and ergocalciferol. Vitamin D is present in relatively few natural foods. One of the main suppliers is meat from fatty fish (e.g. salmon, tuna and mackerel) and oils from fish liver. There are small concentrations of vitamin D in the beef liver, cheese and egg yolks. Vitamin D is mainly found in these foods as vitamin D3 and its metabolite $25(\mathrm{OH}) \mathrm{D} 3$. Vitamin D2 is produced at varying levels from certain mushrooms. Mushrooms with elevated vitamin D2 levels due to ultraviolet light exposure are also available under controlled conditions. Cow's milk and vegetable milk supplement products are improved by vitamin D in the United States and other countries. Ultraviolet light activated mushrooms contain beneficial vitamin D levels. Dietary guidelines usually suggest that a person's entire vitamin $\mathrm{D}$ is absorbed from the mouth because the exposure of the population to sunlight is unpredictable and the amount of healthy exposure to sunlight is unknown in terms of the possibility of skin cancer[18-20]. 


\section{Deficiency}

Vitamin D is either inadequate or deficient, with around one billion people worldwide. Vitamin D deficiency is caused by a deficient intake of vitamin D and a lack of exposure to sunlight. Several children's vitamin $\mathrm{D}$ deficiencies lead to rickets and bone softening and cracking, and a rare condition in the developed world. Vitamin D deficiency is found in elderly people around the world and is still common in children and adults. Deficiency leads to reduced bone mineralization and bone degradation due to bone softening disorders, including childhood rickets and adult osteomalacia. Sun-prevention will result in low blood calcifediol (25-hydroxy-vitamin D). Lack of vitamin $\mathrm{D}$ can lead to a decrease in intestinal calcium absorption of up to $15 \%$. Typically, a person absorbs 60-80 percent when not deficient[21].

\section{Overdose/Toxicity}

Hypercalcemia is a major indicator of the toxicity of vitamin $\mathrm{D}$, which can be detected by increased urination and thirst. If hypercalcemia is not treated, excess calcium concentrations in soft tissues and the body, including the kidneys, liver and heart, cause inflammation and organ damage are the major symptoms of vitamin D deficiency, including anorexia, nausea and vomiting, which are signs of hypercalcemia. Polyuria, polydipsia, fatigue, anxiety, nervousness, pruritus and eventual renal failure may be associated with these disorders. Vitamin D toxicity is also caused by mental retardation in younger children; excess bone production and growth; diarrhoea, irritability, weight loss and severe depression, limiting the absorption of vitamin D and reducing calcium intake. Damage to the kidneys may be permanent. Sunlight absorption does not usually cause toxicity to vitamin D over a long period of time. The levels of vitamin D precursors produced in the skin are balanced and any additional vitamin D produced is degraded [22].

\section{Vitamin E}

Vitamin E is a group of four tocopeherols and four tocotrienols containing a total of eight fat-soluble compounds. Vitamin E deficiency is rare and can typically lead to nervous disorders due to an underlying concern with digestive food rather than a vitamin $\mathrm{E}$ diet deficiency. Vitamin $\mathrm{E}$ is a fat-soluble antioxidant that inhibits reactive oxygen species from cell membrane protection.

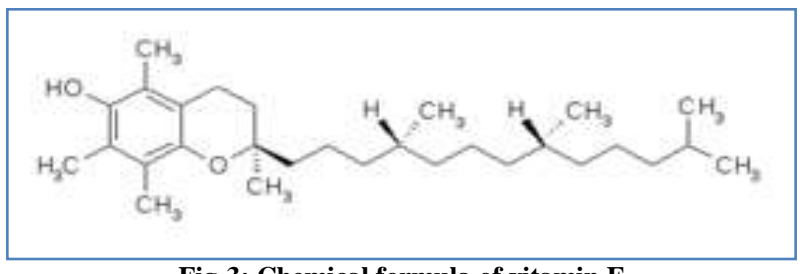

Fig-3: Chemical formula of vitamin $\mathrm{E}$

Government organisations around the world suggest that adults should consume between 7 and 15 $\mathrm{mg}$ of vitamin E per day. Both vitamers are found in the forms by changing the position of the methyl group at the chromanol ring. A chromane double ring is present in all eight of these vitamins, with an $\mathrm{OH}$ group capable of providing a hydrogen atom for the reduction of free radicals and a side chain for hydrophobic membrane penetration. Of the different vitamin E derivatives, the most common forms present in the North American diet are gamma-tocopherol ( tocopherol), but the most biologically active are alpha-tocopherol (tocopherol). Palm oil is a source of tocotrienol[23].

\section{Functions}

Vitamin E may have multiple functions as a supplement. Several biological roles have been postulated, including a fat-soluble antioxidant. Vitamin E serves as a radical scavenger and supplies free radicals with hydrogen $(\mathrm{H})$ atoms. The hydroxyl bond of tochopherols is approximately $10 \%$ weaker than in many other phenols. This weak bond makes it possible for the vitamin to offer the hydrogen atom to the peroxyl radical and other free radicals, thus reducing the harmful effect. Vitamin $\mathrm{C}$ is required to convert tochopheryl radical to tochopherol. Due to their fat soluble nature, they are found in the cell membrane and are protected from free radical attacks [24].

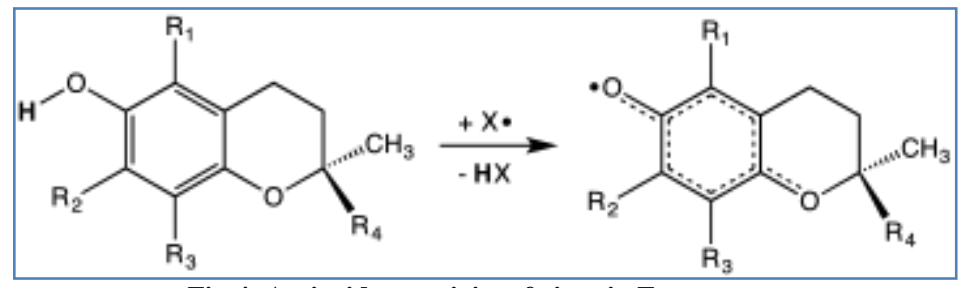

Fig-4: Antioxidant activity of vitamin E

In order to keep the immune system active against viruses and bacteria, the body still needs vitamin E. Vitamin E is also essential in the formation of red blood cells. It helps the body to use vitamin K. It 
also facilitates the widening of blood vessels and stops blood clotting inside. Vitamin $\mathrm{E}$ is used to communicate with cells. It allows them to carry out a variety of essential activities. Vitamin E regulates the expression of a gene that is a regulator of the function of enzymes, such as protein kinase $\mathrm{C}(\mathrm{PKC})$, which plays a role in the smooth growth of muscles, with vitamin $\mathrm{E}$ associated with PKC deficiency for smooth muscle development. Tocochromanol synthesis, a chemical class of 4 tocopherols and 4 tocotrienols in photosynthesizing plants, algae and cyanosystems, is called vitamin $\mathrm{E}$ in the sense of food. Biosynthesis begins with the development of the closed-ring portion of the molecule into homogentisic acid (HGA). The side chain is attached (polyunsaturated tocopherol and tocotrienols). The direction is the same for both the production of gamma and the production of alpha or delta and beta compounds. Plastids are the basis of their biosynthesis[25,26,27].

Various plant sections and species are dominated by various types of tocochromanol. $\alpha$ tocopherol is the primary component of leaves and therefore green leafy vegetables. Chloroplastic membranes are located near photosynthesis. The aim is to prevent the harm caused by ultraviolet sunlight. The presence of $\alpha$-tocopherol does not appear to be appropriate under normal growing conditions, due to the presence of other photo-protective compounds and plants that have been able to synthesise $\alpha$-tocopeherol lost due to mutations, showing normal development. However, the physiological status of plants is higher under stressful conditions of development, such as droughts, high temperatures or oxidative stress caused by salt, where the plant is capable of providing natural synthesis [28].

Seeds are rich in lipids for germination and early growth of energy. Tocochromanols protect seed lipids from oxidation and rancidity. The presence of tocochromanols increases the survival of the seeds and promotes good germination and development. Gammatocopherol is dominant in seeds of most plant species, although there are exceptions. There is more $\gamma$ tocopherol for canola, maize and soya bean oils than $\alpha$ tocopherol, but the opposite applies to safflower, sunflower and olive oils. Palm oil is unusual in traditional food oils because the tocotrienol content is higher than the tocopherol content. The quality of seed tocochromanols also depends on environmental stressors. Dryness or higher temperature changes, e.g. the value of $\alpha$-tocopherol and $\gamma$-tocopherol of nuts in almonds, are increased [29].

\section{Sources}

Plant-based oils, nuts, beans, berries and vegetables contain vitamin $E$. Rich sources of vitamin $E$ include wheat germ oil, sunflower, safflower and soy oil, sunflower seeds, almonds, peanuts, peanut butter, beet greens, collard greens, spinach, cabbage, red bell pepper, asparagus, mango and avocado[30].

\section{Deficiency}

Vitamin E deficiency is rare in human being. For example, mutations in genes responsible for the transport of alpha-tocopherol (TTP) proteins are hereditary metabolism abnormalities. A progressive neurodegenerative disease called vitamin E deficiency ataxia (AVED), through the intake of normal amounts of vitamin E, occurs in humans with this genetic defect. Dietary supplements require large amounts of alphatocopherol to compensate for lack of alpha-TTP. Vitamin E deficiency due to malabsorption or metabolism may cause nerve problems due to poor electrical nerve pulses due to changes in the structure and function of the nerve membrane. Vitamin $\mathrm{E}$ deficiency may cause, in addition to ataxia, peripheral neuropathy, myopathy and impaired immune response [28].

\section{Toxicity/overdose}

The toxicity of vitamin $\mathrm{E}$ absorbed through natural sources is not reported. Many adults with a dose of $22 \mathrm{IU}$ per day higher than RDA use multivitamins or separate vitamin E supplements that produce 400-1000 IU per day. Negative side effects of additional use in healthy people have not been reported. There is an increased risk of bleeding b using its supplements (1000 $\mathrm{mg}$ /day) along with blood thinning drugs (e.g., warfarin). This is why the upper limit of any type of tocopherol supplement has been established for adults 19 years of age and older up to $1000 \mathrm{mg}$ daily (1465 IU)[31].

\begin{abstract}
Absorption
Vitamin E is hydrophobic and is ingested in the same way as other food lipids. It is ingested by small intestinal cells, inserted into chylomicrons, and transferred to the blood by lymphatics after the solubilization of bile acids. When in action, chylomicrons release vitamin $\mathrm{E}$ and a large amount of the liver is taken to lipoprotein, where it is repackaged to very low densities and secreted back into the blood. As a result, vitamin $E$ is transmitted through a number of lipoproteins in the blood produced by tissues in the body. Vitamin E is stored in fat droplets of the adipose tissue[23].
\end{abstract}

\section{Vitamin K}

The complete description includes the final alteration of the gamma-glutamyl carboxylase enzyme, which uses vitamin $\mathrm{K}$ as a cofactor, of the so-called "Gla proteins." Vitamin K deficiency indicates the existence of non-carboxylated proteins. Carboxylation helps them bind calcium ions (chelate) that cannot be bound otherwise. Blood coagulation is severely compromised without vitamin $\mathrm{K}$ and spontaneous bleeding occurs. The study indicated that vitamin $\mathrm{K}$ deficiency may cause bone decay and possibly induce 
osteoporosis, which may facilitate artery and other soft tissue calcification.

Chemically, 2-methyl-1,4-naphthoquinone (3-) is part of the vitamin $\mathrm{K}$ chain. Vitamin $\mathrm{K}$ supplies two natural vitamins: $\mathrm{K} 1$ : phylloquinone and $\mathrm{K} 2$ : menaquinone. Vitamin $\mathrm{K} 2$ consists, in turn, of a variety of molecular subtypes linked to the isoprenoid groups of atoms in different lengths of the carbon side chain. Menaquinone-4 (MK-4) and menaquinone-7 (MK-7) are the two most widely studied vitamins [27].

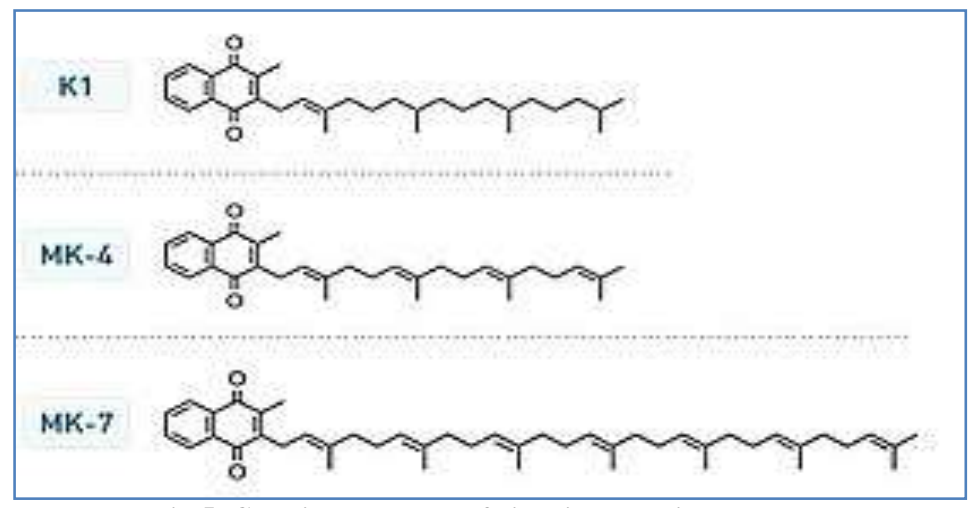

Fig-5: Chemical structure of vitamin $\mathrm{K}$ and its analogues

Vitamin $\mathrm{K} 1$ is produced in a plant and, as it is directly involved in photosynthesis, is present at the highest levels in leafy green vegetables. It is useful in animals as a supplement and serves the standard role of vitamin $\mathrm{K}$ in the manufacture of blood proteins. It can also be transformed into a vitamin $\mathrm{K} 2$ form of MK-4 (known as menaquinone). K1 can also be transformed into MK-4 by bacteria in the intestinal flora. Bacteriathat use them during anaerobic breathing can only make up all types of K2 other than MK-4. The synthetic form of vitamin $\mathrm{K}$, vitamin K3 (menadione), has been used to treat vitamin $\mathrm{K}$ deficiency, but because it interferes with the action of glutathione, it has not been used in this way [18].

\section{Functions}

Vitamin $\mathrm{K}$ is one of the drugs used to treat anticoagulant warfarin overdose bleeding. It can be administered intravenously or subcutaneously through the mouth. In cases where the patient's international normalised ratio (INR) is $<10$ and no significant bleeding is detected, oral vitamin $\mathrm{K}$ is used. Phylloquinone (K1) or menaquinone (K2) was able to reverse the anticoagulant function of warfarin. It acts by inhibiting the synthesis of vitamin $\mathrm{K}$ to reduce the active vitamin $\mathrm{K}$ in the body and tissue and therefore vitamin $\mathrm{K}$ deficiency[12].

Vitamin $\mathrm{K}$ in the form of gammacarboxyglutamate (Gla) is required for the carboxylation of certain proteins in animals. The modified parts of these proteins are known as Gla domains and these domains are typically involved in calcium binding and are vital for the biological function of all known Gla proteins.

Additionally vitamin $\mathrm{K}$ (often more active in oral doses) reverses warfarin-induced vitamin $\mathrm{K}$ deficit and reduces the desired anticoagulant function of warfarin and related drugs. Small amounts of vitamin K are offered to warfarin ingested patients, which helps to improve the predictability of drug action. The correct anticoagulant action of the medicine depends on the intake of vitamin $\mathrm{K}$ and the intake of the drug and must be individualised for each patient due to different absorption. Warfarin and vitamin $\mathrm{K}$ have a maximum effect 2 or 5 days after dosing. In the first 24 hours following administration, either warfarin or vitamin $\mathrm{K}$ has a profound effect [29].

Vitamin $\mathrm{K}$ is also included in the proposed treatment protocol for rodenticide poisoning (coumarin poisoning). Treatment of vitamin $\mathrm{K}$ will only be appropriate for persons who have intentionally ingested significant amounts of rodenticide or unknown rodenticide. In order to prevent harmful effects of rodenticide toxicity, oral vitamin $\mathrm{K} 1$ is given to patients and, in the case of "superwarfarin" rodenticides, such as brodifacoum, this dose can often be extended for up to nine months. As it has fewer side effects, oral vitamin $\mathrm{K} 1$ is preferred over other vitamin $\mathrm{K} 1$ administration pathways [30].

Vitamin $\mathrm{K} 1$ (phylloquinone) is an essential chemical in green plants as a precursor to the majority of vitamin Ks in nature that acts as an electron to accept photosystem I during photosynthesis. Vitamin K1 is therefore present in photosynthetic tissues in large quantities of plants (leaf leaves, dark green vegetables such as roman salads, kale and spinach), but much less so in other plant tissues (roots, fruit, etc.). There's very little Iceberg lettuce about it. In animals where there is a very different biochemical reaction, the role of phylloquinone in plants does not seem to resemble its potential for metabolic and biochemical activity [31]. 


\section{Sources}

Vitamin $\mathrm{K}$ is found in the following foods: green leafy vegetables such as kale, spinach, turnip greens, berries, Swiss chard, mustard greens, parsley, rosemary and lettuce with green leaves, vegetables such as Brussels sprouts, broccoli, colic flowers and cod. Fish, liver, beef, eggs and cereals contain smaller quantities. Bacteria also produce vitamin $\mathrm{K}$ in the lower intestinal tract.

\section{Deficiency}

Normal diets are not typically vitamin K-free, and primary deficiencies are rare in healthy adults. The risk of deficiency in newborn infants is increased. Additional groups with an enhanced incidence of vitamin $\mathrm{K}$ deficit comprise people with liver or disease (e.g. alcohol), cystic fibrosis or intestinal disorders, or who have previously undergone abdominal surgery. Secondary vitamin $\mathrm{K}$ deficit may take place in people with Bulimia who have strict diets and anticoagulants. Vitamin $\mathrm{K}$ deficiency is characterised as hypoprothrombinemia, which increases prothrombin time and may lead to coagulopathy. K1 deficiency includes anaemia, vomiting, nosebleeds and gum bleeding in all races, and extreme menstrual bleeding in females [28].

Lower levels of $\mathrm{K} 2$ are associated with coronary heart disease. Vitamin K2 (like menaquinone MK-4-MK-10) is inversely associated with extreme calcification and death. The risk of osteoporosis was not affected by lower vitamin $\mathrm{K}$ intake of food or by people who were treated with warfarin - a vitamin $\mathrm{K}$ blocker and bone mineral density and fractures were measured. Long-term vitamin $\mathrm{K}$ antagonists were associated with a lower incidence of cancer during anticoagulation therapy [18].

\section{Toxicity}

Vitamin $\mathrm{K}$ toxicity is quite high. Menadion, which is ineffective in humans, is the only toxicity recorded. Its toxicity is expected to be linked to its water-soluble properties. Jaundice, hyperbilirubinemia, hemolytic anaemia and kernicterus are common in adolescents when exposure occurs. The toxicity function of menadione is to increase the absorption of oxygen into the liver, resulting in a significant increase in lipid peroxidation, resulting in cell damage and death. The related symptoms of vitamin $\mathrm{K}$ toxicity result in damage to the hepatocyte [28]

\footnotetext{
Absorption

Vitamin K1 is absorbed in the small intestine by jejunum and ileum and is processed in the body's fatty tissue like other lipid-soluble vitamins (A, D, and E) when it reaches the body through food in the individual's diet. Previously, nutritional deficiency was extremely rare because the small intestine was severely impaired and the drug was malabsorbed. Other risk deficiency categories are those exposed to decreased
}

natural intestinal microbiota development of $\mathrm{K} 2$ as seen in large-spectrum antibiotic use. Taking large-scale antibiotics will decrease the production of vitamin $\mathrm{K}$ in the intestine by almost 74 percent in individuals relative to those who do not. Vitamin K-low diets often limit the concentration of body vitamin K. Elderly people have reduced levels of vitamin K2 [31].

\section{CONCLUSION}

Some reports list 14 vitamins, including choline and other major health authorities reported 13 vitamins: A, B1, B2, B3, B5, B6, B7, B9, B12, C, D , E and $\mathrm{K}$. Fat soluble vitamins are processed through the intestine using lipids (fats). The body can accumulate vitamins $\mathrm{A}$ and $\mathrm{D}$ that can lead to dangerous hypervitaminosis. Fat-soluble malabsorption vitamin deficiency is especially important in cystic fibers. This review article helpful to understand the biochemical functions of fat soluble vitamins for the human body.

\section{REFERENCES}

1. Aguilera-Méndez, A., Fernández-Lainez, C., Ibarra-González, I., \& Fernandez-Mejia, C. (2012). The chemistry and biochemistry of niacin (B3). In B Vitamins and Folate (pp. 108-126).

2. Angeline, M. E., Gee, A. O., Shindle, M., Warren, R. F., \& Rodeo, S. A. (2013). The effects of vitamin $\mathrm{D}$ deficiency in athletes. The American journal of sports medicine, 41(2), 461-464.

3. Galli, F., Azzi, A., Birringer, M., Cook-Mills, J. M., Eggersdorfer, M., Frank, J., ... \& Özer, N. K. (2017). Vitamin E: Emerging aspects and new directions. Free Radical Biology and Medicine, 102, 16-36.

4. Gast, G. C. M., de Roos, N. M., Sluijs, I., Bots, M. L., Beulens, J. W., Geleijnse, J. M., ... \& van der Schouw, Y. T. (2009). A high menaquinone intake reduces the incidence of coronary heart disease. Nutrition, Metabolism and Cardiovascular Diseases, 19(7), 504-510.

5. Holick, M. F., \& Chen, T. C. (2008). Vitamin D deficiency: a worldwide problem with health consequences. The American journal of clinical nutrition, 87(4), 1080S-1086S.

6. Iqbal, K., Khan, A., \& Khattak, M. M. A. K. (2004). Biological significance of ascorbic acid (vitamin C) in human health-a review. Pakistan Journal of Nutrition, 3(1), 5-13.

7. Jones, G. (2008). Pharmacokinetics of vitamin D toxicity. The American journal of clinical nutrition, 88(2), 582S-586S.

8. McGuire, M., \& Beerman, K. A. (2012). Nutritional sciences: from fundamentals to food. Cengage Learning.

9. Peter, S., Friedel, A., Roos, F. F., Wyss, A., Eggersdorfer, M., Hoffmann, K., \& Weber, P. (2016). A systematic review of global alphatocopherol status as assessed by nutritional intake levels and blood serum concentrations. Int. J. Vitam. Nutr. Res, 14, 1-21. 
10. Pittas, A. G., Chung, M., Trikalinos, T., Mitri, J., Brendel, M., Patel, K., ... \& Balk, E. M. (2010). Systematic review: vitamin D and cardiometabolic outcomes. Annals of internal medicine, 152(5), 307-314.

11. Tardy, A. L., Pouteau, E., Marquez, D., Yilmaz, C., \& Scholey, A. (2020). Vitamins and minerals for energy, fatigue and cognition: a narrative review of the biochemical and clinical evidence. Nutrients, 12(1), 228.

12. Yamada, K. (2013). Cobalt: its role in health and disease. In Interrelations between essential metal ions and human diseases (pp. 295-320). Springer, Dordrecht.

13. Zetterström, R. (2009). Nobel Prize 1937 to Albert von Szent- Györgyi: identification of vitamin C as the anti- scorbutic factor. Acta Padiatrica, 98(5), 915-919.

14. Rafeeq, H., Arshad, M. A., Amjad, S. F., Ullah, M. H., Muhammad, H., Imran, R. K., ... \&amp; Ajmal, H. Effect of Nickel on Different Physiological Parameters of Raphanus Sativus.

15. Rafeeq, H., Tanvir, K., Khan, M. A. B., Basit, I., U1, Q., Ain, F. F., ... \&amp; Siddique, S. An Effective Approach towards Heavy Metals and their Effects on Different Organs of the Body.

16. Hussain, A., Rafeeq, H., Asghar, A., Ullah, S., Imtiaz, U., Ullah, H., \&amp; Ilyas, M. D. Combined inhibitory potential of Ammonium thiosulphate and 2-chloro-6-(trichloromethyl) pyridine on ureases activities.

17. Ghani, U., Bukhari, S. S. H., Ullah, S., Rafeeq, H., Saeed, M. M., Amjad, A., \&amp; Taufiq, T. (2019). A review on Nutraceuticals as a Therapeutic Agents. International Journal of Biosciences, 15(5), 326-340.

18. Naeem, M., Hayat, M., Azmi, U. R., Ahmed, S., \&amp; Irfan, M. (2019). Molecular Identification of Ten Palm Species using DNA Fingerprinting. Int. J. Pure App. Biosci, 7(1), 46- 51.

19. Ahmad, I., Khan, S., Naeem, M., Hayat, M., Azmi, U. R., Ahmed, S., \& Irfan, M. (2019). Molecular Identification of Ten Palm Species using DNA Fingerprinting. Int. J. Pure App. Biosci, 7(1), 4651. 14.

20. Naeem, M., Hayat, M., Qamar, S. A., Mehmood, T., Munir, A., Ahmad, G., \& Hussain, A. (2019). Risk factors, genetic mutations and prevention of breast cancer. Int. J. Biosci, 14(4), 492-496.

21. Shafiq, S., Adeel, M., Raza, H., Iqbal, R., Ahmad, Z., Naeem, M., \& Azmaai, U. R. (2019). Effects of Foliar Application of Selenium in Maize (Zea Mays L.) under Cadmium Toxicity. In Biological
Forum-An International Journal, 11(2): 27-37.

22. Usman, G., Muhammad, N., Hamza, R., Usman, I., Ayesha, A., Saqib, U., \& Fatima, Q. (2019). A Novel Approach towards Nutraceuticals and Biomedical Applications. Scholars International Journal of Biochemistry, 2(10), 245-252.

23. Uzun, F. G., Kalender, S., Durak, D., Demir, F., \& Kalender, Y. (2009). Malathion-induced testicular toxicity in male rats and the protective effect of vitamins $\mathrm{C}$ and E. Food and chemical toxicology, 47(8), 1903-1908.

24. Naeem, M., Ashraf, A., Safdar, H. M. Z., Khan, M. Q., Rehman, S. U., Iqbal, R., ... \& Ahmad, G. Biochemical changes in patients with chronic kidney failure in relation to complete blood count and anemia.

25. Ghani, U., Naeem, M. Bukhari, S.S.H., Yar, G., Tariq, I., Siddique, S., Nawaz, H.A., Pal, Z.A.A., Nasim, F. and Bukhari, S.A.H. (2019). Prevalence and Risk Factors associated with Hepatitis B and Hepatitis $\mathrm{C}$ and their Correlation with Inflammatory Markers among Southern Region of Punjab. Biological Forum - An International Journal, 11(2): 136-143.

26. Naeem, M., Ali, J., Hassan, M. Z., Arshad, B., Rao, M. H. I., Sarmad, M. S. K., ... \& Hassan, M. U. (2019). Novel Approach towards DNA Barcoding as a Tool in Molecular Biologyand Biological Activities of Cyclotides with Particular Emphasizes at Molecular Level. In Biological Forum-An International Journal, 11(2), 83-96.

27. Sies, H., Stahl, W., \& Sundquist, A. R. (1992). Antioxidant functions of vitamins: Vitamins $\mathrm{E}$ and C, Beta- Carotene, and other carotenoids a. Annals of the New York Academy of Sciences, 669(1), 720.

28. Heart Outcomes Prevention Evaluation (HOPE) 2 Investigators. (2006). Homocysteine lowering with folic acid and B vitamins in vascular disease. New England Journal of Medicine, 354(15), 1567-1577.

29. Fairfield, K. M., \& Fletcher, R. H. (2002). Vitamins for chronic disease prevention in adults: scientific review. Jama, 287(23), 3116-3126.

30. Abushita, A. A., Hebshi, E. A., Daood, H. G., \& Biacs, P. A. (1997). Determination of antioxidant vitamins in tomatoes. Food Chemistry, 60(2), 207212.

31. Brown, B. G., Zhao, X. Q., Chait, A., Fisher, L. D., Cheung, M. C., Morse, J. S., ... \& Frohlich, J. (2001). Simvastatin and niacin, antioxidant vitamins, or the combination for the prevention of coronary disease. New England Journal of Medicine, 345(22), 1583-1592. 